\title{
Two methods for decreasing the flexibility gap in national energy systems
}

\author{
Ilija Batas Bjelić*a, Nikola Rajakovića \\ School of Electrical Engineering Belgrade \\ a University of Belgrade, Belgrade, Serbia \\ e-mail: batas@etf.rs, rajakovic@etf.rs
}

\section{Goran Krajačićb, Neven Duićb}

Faculty of Mechanical Engineering and Naval Architecture

b University of Zagreb, Zagreb, Croatia

e-mail: goran.krajacic@fsb.hr, neven.duic@fsb.hr

\section{Abstract:}

More variable renewable energy sources and energy efficiency measures create an additional flexibility gap and require a novel energy planning method for sustainable national energy systems. The firstly presented method uses only EnergyPLAN tool in order to decrease the flexibility gap in a national energy system. Generic Optimization program (GenOpt $\AA$ ) is an optimization program for the minimization of a cost function that is evaluated by an external simulation program, such as EnergyPLAN, which was used as the second method in this research. Successful strategies to decrease the flexibility gap are verified on the case of the Serbian national energy system using two methods for its structure design: (1) the iterative method, based on heuristics and manual procedure of using only EnergyPLAN, and (2) the optimization method, based on soft-linking of EnergyPLAN with GenOpt ${ }^{\circledR}$. The latter method, named EPOPT (EnergyPlan-genOPT), found the solution for the structure of the sustainable national energy system at the total cost of $8,190 \mathrm{M} €$, while the iterative method was only able to find solutions at the cost in the range of $8,251-8,598 \mathrm{M} €$ by targeting only one sustainability goal. The advantages of the EPOPT method are its accuracy, user-friendliness and minimal costs, are valuable for planners. 
Keywords: variable renewable energy, sustainable energy system, smart grid, EnergyPLAN model, EU 2030 energy policy goals, EPOPT method.

\section{Highlights}

- Heuristic and optimization method for sustainable national energy system structure

- The same input assumptions resulting in different energy system structure

- Both methods are successful in decreasing of the flexibility gap

- The EPOPT method advantages are in the speed, accuracy and planner comfort

- Advanced method for the sustainable national energy policy planning

$\begin{array}{ll}\text { Abbreviations } \\ \text { BMS } & \text { Biomass } \\ \text { CAES } & \text { Compressed Air Energy Storage } \\ \text { CHP } & \text { Combined Heat and Power plant } \\ \text { DH } & \text { District Heating } \\ \text { EE } & \text { Energy Efficiency } \\ \text { FOC } & \text { Fixed Operation Costs } \\ \text { GenOpt } & \text { Generic Optimization program } \\ \text { PHEV } & \text { Plug In Hybrid Vehicle } \\ \text { PHSPP } & \text { Pumped Hydro Storage Power Plant } \\ \text { PV } & \text { Photovoltaic } \\ \text { RE } & \text { Renewable energy } \\ \text { RES } & \text { Renewable Energy Sources } \\ \text { RES-E } & \text { Renewable electricity sources } \\ \text { SHPP } & \text { Small Hydro Power Plant } \\ \text { TPES } & \text { Total Primary Energy Supply } \\ \text { TPEScor } & \text { Export/import corrected TPES value } \\ \text { TPP } & \text { Thermal Power Plant } \\ \text { TVC } & \text { Total Variable Costs }\end{array}$

\section{Introduction}

The transformation of national energy systems faces two challenges: (1) maintaining the positive and (2) reducing the negative outcomes of secure energy supply [1]. Energy system flexibility is constrained by the flexibility of its demand and generation [2]. The introduction of variable renewable energy sources such as wind and solar energy, or energy efficiency measures in line with EU 2030 energy policy goals, will at the same time increase the flexibility gap and reduce the availability of flexible resources in energy systems [2, 3]. However, this should not be perceived as an obstacle in the planning phase. A study shows that up to 80 $\%$ of variable renewable energy sources (RES) can be integrated [4] into a national energy system when all flexibility options are included. Another study shows that it is not feasible to integrate $100 \%$ renewable energy sources into a power system without demand flexibility [5]. Further, Stadler [6] sees no theoretical upper limit for the integration of renewable energies into electricity networks that can be explained by missing control power. Wind power yearly penetration of above $40 \%$, monthly above $61.7 \%$, daily above $102 \%$ and hourly above $135 \%$ has already been recorded in the front-runner Danish energy system $[7,8]$.

The solution to the well-known sustainable energy system planning problems lies in further integration of electricity, transport and heating systems into one system with increased 
flexibility [9-12]. Mancarella [9] identified advantages of smart energy systems through their "multi-energy" perspective which increases systems efficiency and flexibility. The flexibility of a power system [13, 14], positive to increase and negative to decrease available energy [15], an inherent feature of their design and operation, is defined as the ability to: (1) "cope with events of imbalance between electricity supply and demand while maintaining the system stability in a cost-effective manner" [3, 16]; (2) "maintain that balance even during times when demand or supply change rapidly or widely" [17, 18]; (3) "benefit from variability in production without generation of excess electricity production" [19] which one will be used.

The flexibility gap [3] on the system and local scale [20] might be covered by sixteen other flexibility options grouped in five categories: supply, demand, energy storage, grid and system operation principles or their mix [2]. Flexibility options are found within the electricity sector (dispatchable power plants, demand response, energy storage and grid interconnection), including renewables themselves, and outside the electricity sector, in the area of transportation and heating [17]. Flexibility options may be summarized as in [21] but concurrent flexibility options [22-25] are sorted as a supply curve, analogous to the generation supply curve. Another flexibility source prioritization can be found in [26, 27], including overgeneration from renewable energy sources [28].

Flexibility is also provided by larger balancing areas, access to neighboring markets, fast energy market, improved market design, demand response, strategic renewable energy curtailment, new ancillary services and products, flexible conventional generation units, and storage [29]. The flexibility served at the local level has been simulated and verified using an operation optimization model in [30]. Selling excess productions to the European grid may look as a solution but the problem will remain if each country adopts the same policy [19].

There are different metrics for flexibility, such as "net flexibility resource" [31], storage capacity, maximum positive residual load, and excess energy production [19, 32]. The excess energy production duration curves are characterized by the annual value, maximal hourly value, duration over the year and the slope. Looking at duration curves, one can compare the flexibility of different national energy system scenarios. Alternative flexibility options can be analyzed with generation simulations [29] and this gap can be quantified with CEEP using the EnergyPLAN tool. EnergyPLAN has been validated in many studies explained in detail in [33]. GENOPT® has also been validated e.g. [34-37] and well documented [38].

Utilization of capacities obtained from optimal operation during one year hour by hour simulation becomes the main decision driver in the investment optimization. Flexibility is then obtained as a positive side effect of cost minimization [15], which might be a feature of the EPOPT method. The iterative method, based on heuristics presented in [19] has been standard for EnergyPLAN users in the process of performing national energy analysis and recommendation of the strategies in South East Europe [39], Romania [40], Serbia [41], Croatia [42] and many other countries [43]. In this article the heuristic method is compared to a new optimization method (EPOPT) to look at how they reduce the flexibility gap and costs in sustainable national energy systems. In other words, we first look at how the planner community uses heuristic methods with EnergyPLAN to design technically flexible smart national energy systems and then how an optimization method may be applied to help planners avoid repetitive tasks and obtain more accurate solutions. The article shows how an energy system can benefit from large-scale integration of variable renewable energy sources and energy efficiency measures applied to the optimal amounts. EnergyPLAN simulations have been carried out to quantify the annual total system costs (annual financial balances), annual energy balances and annual operation of selected flexibility options. The obtained result in one case study indicates that the EPOPT method has advantages over the iterative method in improved accuracy, shorter duration (also user-friendliness for the planner) and further cost reduction based on better utilization. The planner community is kindly invited to use the EPOPT method in more case studies in other counties and to validate its quality 
against state of the art methods for national energy system optimal planning. Based on these advantages the EPOPT method may become the most popular among national energy systems planners in the EU or other sustainable governance frameworks, boosting the usage of EnergyPLAN and GENOPT®. Ultimately, the European Commission, governments and citizens will be key beneficiaries.

\section{Method}

\subsection{Measures for energy system transformation}

Smart energy system measures refer to technically optimal mixing of variable renewable energy sources, using multi-energy carrier flexibility options, using design and operation of energy system differently and using all smart grid technologies for grid stabilization. A different design of an energy system means the utilization of different generation options. On the other hand, different operation of the energy system means choosing: (1) the operation optimization strategy (market or technical), (2) grid stabilization requirements, (3) critical excess electricity production (CEEP) balancing strategies, etc. Measures towards smart energy systems have potential to replace fossil fuels, to improve fuel efficiency and they should be combined with energy conservation measures and system efficiency improvements in order to become relevant for the future energy systems [10]. Furthermore, their mix has an impact on the flexibility requirements [14], which has to be minimized. Therefore we search for a technoeconomically optimal mix between wind and solar photovoltaic (PV). Future national energy systems in year 2030 should be designed to meet indicative EU level designated targets of at least $27 \%$ energy from renewable energy sources in final energy consumption, $40 \% \mathrm{CO}_{2}$ emission reduction in comparison to 2009 , and energy efficiency improved by $27 \%$ [44] in comparison to the current outlooks [45]. Fuel consumption and $\mathrm{CO}_{2}$ emissions reductions are already shown possible in the case of the Danish national energy system [46][46]. Although much research has been done in the area of optimal energy systems, it is still an open question which energy sources and which types of efficiency measures will be used in an energy master plan in order to reach the designated targets. All conventional and new supply side technologies can create the flexibility gap, since they are characterized by a flexibility coefficient [47]. Apart from adding variability to the supply side, the demand side energy efficiency measures also create the flexibility gap [20]. For example, these measures can narrow down electricity consumption, which may be used for demand response. This means that all flexibility options have to be coordinated because their benefits are related to the whole energy system [48]. Each technical measure project (for example a storage project) might be profitable for the investor but from the system perspective may be a waste of money that could be invested in other technical measures. It is essential to show that there is a limit of quantity for each profitable technical measure at which it does not contribute to designated goals. Correct system flexibility assessment is data intensive and requires detailed system modeling at the hourly level, which is an acceptable tradeoff between computability and quality [23]. Since it is difficult to accurately address flexibility, methodologies may be compared only relatively to each other.

Different design of sustainable national energy systems involves decisions on optimal investment into technical measures. The decision variables are grouped into three decision vectors: renewable energy measures (RES), energy efficiency measures (E) and structural measures (S) shown in Fig 1.

\subsection{EnergyPLAN methodology}

For the modeling of a national energy system a multi energy system [9] hourly simulation model called EnergyPLAN [49] is used. The EnergyPLAN simulations are performed with technically optimized operation of closed energy system which calculates the flexibility gap as a 
value of CEEP. EnergyPLAN enables modeling of different operation principles and smart grid functions [50]. In addition, it models operation principles for combined heat and power, heat pumps and heat storage capacity [19]. Smart district heating systems [51] can help in CEEP reduction by replacing heat production by other devices. The same can be achieved by electrification of the transport sector $[19,51]$. The operation duration curves were obtained after EnergyPLAN ran an output screen for 8784 hourly values after sorting like in [52]. $\mathrm{CO}_{2}$ emission reductions are calculated according to the EnergyPLAN and compared against the European Commission 2030 framework for climate and energy policies [44]. A detailed algorithm of flexible demand in EnergyPLAN can be found in [53]. Modeling of the variable renewable energy source was done without spatial smoothing [14] and without normalization [32], which tend to show flexibility gap higher than it is. For the base scenario in the case study of the Serbian sustainable national energy system the base year model [54] was validated against the IEA balances.

\subsection{Heuristic - EnergyPLAN Iterative method}

From a technical point of view, the optimal combinations of variable renewable energy sources is the scenario when the CEEP is minimal [19]. The heuristic planning method, or the so-called "iterative method" was previously shown in the $[39,55]$. This method starts with a strategic framework set within a governmental document such as an energy strategy [45] or a national energy plan. Planners then opt for a system intervention, picking the technical measures by trial and error or heuristics and start the iterative method to find their optimal mix and reach the designated goals [44]. This method treats goal achievement - RES share in GFEC, TPES savings and $\mathrm{CO}_{2}$,- separately in three steps.

Usually, first the needed increase in the RES production is calculated assuming the savings in GFEC after assumed TPES reduction. Different mixes of renewable energy sources are simulated with EnergyPLAN to calculate the CEEP curves at a certain number of levels of variable renewable energy penetration, e.g. 5, 10,15 TWh. Later approximations are made, first to fit the desired penetration level, and second to fit among optimum for different penetration levels. In the final step the technical optimum is obtained at the intersection between these two. This is shown in detail in [56]. The main scenario assumptions are shown in Table 2.

Then a technically optimal and a quasi economically optimal share of RES is calculated resulting with a set of RES technical measures. Secondly, the technical energy efficiency measures are calculated to meet the GFEC reduction target. Thirdly, the CO2 goal is compared with achieved CO2 savings, and eventually, more technical measures are suggested if the goal has not been reached. If the goal has already been reached, no additional measures have to be applied. The problem is that these steps are performed separately, usually with different software tools [57] (e.g. the tool FORECAST has been used for energy efficiency technical measures [58]). The outcome is such that some technical measures chosen to meet one goal, usually affect the other two goals. This means that sometimes unnecessary measures will be applied, producing unnecessary costs. For example, technical measures of additional RES production address all three goals [59,60]. If RES production is increased to decrease $\mathrm{CO} 2$ emission, for example, then some energy saving measures are useless for reaching the designated target. Also, vice versa, if some energy efficiency measures are applied on the demand side, GFEC will be decreased, making some RES production useless for reaching the designated target. Additional drawback of this method is that it searches for the flexibility in the sustainable national energy system after all three goals are met separately one by one, when flexibility gap has been created. The flexibility thus takes the form of additional costs. The solution to these problems requires a novel energy planning method.

\subsection{EPOPT method - EnergyPLAN soft-linked to GENOPT ${ }^{\circledR}$.}


The EPOPT method, which was presented in [43, 61, 62], utilizes the simplicity of the EnergyPLAN and powerful generic optimization program GenOpt $₫$ suitable for mathematical modeling. Both of them are used already and verified in many articles [61]. The method uses EnergyPLAN which has been soft-linked with GenOpt ${ }^{\circ}$ adding the investment optimization capability to the planning of national energy systems. So far this capability has existed in the planning of micro power systems such as HOMER [63]. This method uses a simulation-based optimization procedure which does not need additional effort from the planner in repetitive tasks. The procedure of creating scenarios for EnergyPLAN with different energy system design is done automatically through the optimization algorithm that is executed in GENOPT® platform. The planner is supposed to define the optimization criteria, decision variables and optimization constraints before engaging in the optimization procedure. The optimization planner may then see what the optimal energy system design is under the assumed input data.

The objective function of the EPOPT method for optimal national energy system structure under the sustainability constraints is given in Eq. 1-5.

$$
\min _{\boldsymbol{R E S} \boldsymbol{S}_{2030}, \boldsymbol{E} \boldsymbol{E}_{2030} \in P} C_{\text {total }}=C A P E X_{2030}\left(\boldsymbol{R E} \boldsymbol{S}_{2030}, \boldsymbol{E} \boldsymbol{E}_{2030}\right)+O P E X_{2030}\left(\boldsymbol{R E} \boldsymbol{S}_{2030}, \boldsymbol{E} \boldsymbol{E}_{2030}\right)
$$
s.t.

$$
\begin{gathered}
\Delta^{1}(\boldsymbol{R E} \boldsymbol{S}, \boldsymbol{E} \boldsymbol{E})=T P E S_{2030}(\boldsymbol{R E} \boldsymbol{S}, \boldsymbol{E} \boldsymbol{E})-0.73 * T P E S_{2030}(0,0) \leq 0 \\
\Delta^{2}(\boldsymbol{R E} \boldsymbol{S}, \boldsymbol{E} \boldsymbol{E})=0.27 * G F E C_{2030}-E_{R E S, 2030}(\boldsymbol{R E} \boldsymbol{S}) \leq 0 \\
\Delta^{3}(\boldsymbol{R E} \boldsymbol{S}, \boldsymbol{E} \boldsymbol{E})=Q_{C O 2,2030}(\boldsymbol{R E} \boldsymbol{S}, \boldsymbol{E E})-0.60 * Q_{C 02,2009} \leq 0 \\
0 \leq \boldsymbol{R E} \boldsymbol{S}_{2030} \leq \boldsymbol{R E} \boldsymbol{S}_{\text {max }}, 0 \leq \boldsymbol{E} \boldsymbol{E}_{2030} \leq \boldsymbol{E} \boldsymbol{E}_{\text {max }}
\end{gathered}
$$

where:

$C_{\text {total }}$ - the total annualized costs of the energy system, cost function;

CAPEX $X_{2030}$ - the total annualized investment costs for the year 2030;

OPEX $X_{2030}$ - the total annualized operation and maintenance costs for the year 2030;

TPES ${ }_{2030}$ - the total primary energy supply in the year 2030 , dependent variable;

$E_{R E S, 2030}$ - the energy from renewable sources in 2030, dependent variable;

$Q_{\mathrm{cO} 2,2009,} Q_{\mathrm{cO} 2,2030}-\mathrm{CO}_{2}$ emissions in 2009 and 2030, respectfully, dependent variables;

$\boldsymbol{R} E \boldsymbol{S}_{2030}$ - renewable energy measures vector in 2030 , decision variable;

$\boldsymbol{E E}_{2030}$ - energy efficiency measures vector in 2030 , decision variable;

$\boldsymbol{R} \boldsymbol{E} \boldsymbol{S}_{\max }, \boldsymbol{E} \boldsymbol{E}_{\max }$ - technical maximum vector for renewable energy and energy efficiency measures, respectively;

$P$ - set of technical energy policy measures.

Besides the above presented step one (1) (optimization of a sustainable national energy system), EPOPT method steps consist of: (2) running EnergyPLAN from GenOpt ${ }^{\circledR}$, (3) setting up the investment optimization problem in GenOpt $\AA$, (a) minimizing total system costs (cost function), (b) choosing a policy mix (decision variables and their constraints), (c) 
implementing the policy constraints (dependent variables, post-processing), (d) implementing the technical measures' additional costs (pre-processing), (e) implementing energy efficiency measures, and (4) setting up the optimization algorithms, which are given in the $[61,62]$.

In this article the optimization algorithm, optimization criteria, decision variables, optimization constraints and assumptions are the same as in [61].

From a philosophical point of view, model validation is a complex methodological issue associated with all simulation techniques [64]. Authors are therefore concentrated [65] on the confirmation of the EPOPT model from one case study to another, testing the usefulness of the method, thus gradually increasing model validity. The EPOPT model cannot be validated from a historical perspective for two reasons: (1) it is not possible to invest into the realization of a sustainable national energy system just for the validation purpose, (2) energy policy decisions in the past may have not been based on the techno-economical optimality but rather on decisionism [66].

The EPOPT method has been tested for its validity with sensitivity analysis to exogenous assumptions and confirmed by scientific journal and dissertation expert reviewers [61, 62]. Furthermore, its results are validated against likelihood studies in subchapter 7.1 in [62]. For the purpose of more detailed validation of the complex algorithm of the EPOPT method, the source code is documented in the Appendix III [62].

\subsection{Scenarios for decreasing flexibility gap}

In order to compare the heuristic method and the optimization EPOPT method for the optimal design of an energy system [19,61], two scenarios were created in EnergyPLAN, assuming the same input data shown in Table 1:

1. OPTIMAL, optimal scenario created using the optimization method EPOPT according to [61, 62], which is explained in Subchapter 2.4, and

2. MANUAL, manually created scenario based on the heuristics and iterative method [19], which is explained in Subchapter 2.3.

Firstly, the OPTIMAL scenario was created after multiple simulations using the EPOPT method. Secondly, the MANUAL scenario was created using the OPTIMAL scenario, whereby optimal values were manually replaced with ones previously obtained from the iterative method. Since the iterative method included only technical optimization, without calculation of additional costs for energy efficiency and structural measures, these were calculated externally to EnergyPLAN for the MANUAL scenario, based on the same specific costs used during calculations in the OPTIMAL scenario, which are given in [61]. The market optimization control strategy was applied in both scenarios. It would have been possible to create the MANUAL scenario first and compare it with the OPTIMAL one. The conclusions, however, would have remained the same.

\section{Results}

Two methods to design an optimal energy system were applied and the results are shown in the following scenarios: MANUAL, with the heuristic iterative method, and OPTIMAL, where the EPOPT method was used.

The total system costs of a sustainable national energy system based on the iterative method and heuristics are shown in Fig 2. left, while optimal results are shown on the right.

The EPOPT method differs from the parametric run because all decision variables (usually more than two) are altered until optimal system design is found. 
The results from many different combinations of decision variable alternation generate families of scenarios. However, for the sake of simplicity Fig 2. (right) shows only two decision variables: PV and WIND. Looking at the values of just two decision variables, one may see huge differences in total system costs for the constant values of two decision variables. This can be seen more clearly in Fig. 3, looking at the total cost function for different values of decision variables. Looking at scenarios $0-100$ it can be observed that total costs vary between 8,200 and 9,300 M€ for the constant values [0,0] of two decision variables: PV and WIND. This contradicts Fig. 2. (left) and the iterative method conclusion.

The iterative method of total system cost calculation shows isocost lines for different values of two decision variables: solar PV power [0-2,500] MW and WIND [0-2,500] MW, where $[\mathrm{L}, \mathrm{U}]$ indicates lower and upper limits. Such procedure in which only two decision variables are altered while others are kept constant is called a parametric run. Parametric runs are performed with results in the range between 8,251 $\mathrm{M} €$ and 8,598 $\mathrm{M} €$. Those quasi minimal total system costs are obtained at $[0,0]$ without guarantee of reaching designated goals. The smooth cost plane indicates that total system costs could be minimized by picking a combination of decision variable values from the plane. However, this is not true because the variation of two decision variable values does not alter other decision variables.

The results show that total system costs may be different in different scenarios for the constant value of a decision variable, because other variables are changed. Even though the two decision variables may have constant values in the two scenarios, the total system costs are different. Total system costs depend on all decision variables and they are constant when all decision variables are constant. Minimal total system costs obtained during the EPOPT procedure are 8,190 M€ but without constraint satisfaction. The minimal total system costs that are within constraint satisfaction are 8,265 M€. This is observed in Fig. 4, where all decision variables from the EPOPT method are shown together against the results of the iterative procedure.

All scenarios shown in Fig. 4. are sustainable. The red arrow shows the area of the results previously obtained using the iterative method and the variation of the two decision variables. Although it was previously shown that iterative method does not ensure constraint satisfaction, these results also show that the iterative method does not assure the minimization of total system costs, because minimal system costs are found for the values of decision variables out of the parametric run area. On the other hand, some sustainable scenarios, with constraint satisfaction, might be with higher total cost, up to 9,258 $\mathrm{M} €$. This shows that sustainability criterion and cost minimization are different criteria for national energy systems.

Additionally, this figure shows in more detail that the total system cost for the values of decision variables that are within lower and upper limits, are out of the area of the results obtained using the iterative method, as a result of variation of other decision variables. Fig. 5.

The total system cost comparison for the scenario MANUAL and OPTIMAL is shown in

The financial balance shows that total annual system costs, including total variable costs, investment costs and fixed operational cost could not be lower than in the OPTIMAL scenario. Although in the MANUAL scenario total variable costs are decreased for 1,501 $\mathrm{M} € / \mathrm{a}$, investment costs and fixed operational costs are increased for 1,610 M€/a $(1,489$ $\mathrm{M} € / \mathrm{a}$ and $121 \mathrm{M} € / \mathrm{a}$ respectfully), resulting in a total annual system cost increase of $109 \mathrm{M} €$. achieving in total $8,375 \mathrm{M} €$. This is only one example showing what is true for many other scenarios that may be generated manually. 
The differences in energy balances, between MANUAL and OPTIMAL scenarios are shown in Fig. 6.

The yearly energy balances show how electricity market is significant for optimal energy system design. Although in the MANUAL scenario TPES is lower, total energy savings are higher, and production from RES-E and biomass is higher, this scenario was not an optimal mix of decision variables for national energy system design. The optimal national energy system design (the OPTIMAL scenario) heavily relies on electricity market exchange. Under the assumed market prices and their historical yearly fluctuations, import was preferred to own production. This should not be a general conclusion but an illustrative example. The effect lies in the calculation of $\mathrm{CO}_{2}$ emission from the imported energy. In the case presented here, the assumption is that energy import is not associated with emissions, which are counted into exporters' emission balance. Therefore, TPEScor is higher in the OPTIMAL scenario, then in the MANUAL one.

The effects of the optimally designed national energy system on the operation of two moderators - PHSPP and grid connected electric vehicle - are illustrated in Fig. 7.

The utilization of both moderators in the OPTIMAL scenario is higher than in the MANUAL scenario. Annual operation of a PHSPP pump and turbine in the OPTIMAL scenario was 1.57 and $1.1 \mathrm{TWh} / \mathrm{a}$ respectfully, which is equal to yearly utilization of $27.5 \%$ and $19.2 \%$. In the MANUAL scenario, the annual operation of a PHSPP pump and turbine was lower -1.45 and $0.97 \mathrm{TWh} / \mathrm{a}$ respectfully, which is equal to yearly utilization of $25.5 \%$ and $16.9 \%$. The utilization of the smart chargers of grid connected electric vehicle fleet was $14.7 \%$ in the OPTIMAL scenario and $24 \%$ in the MANUAL scenario. The difference might result from different penetration of variable renewable energy sources in the two scenarios. The utilization of smart dischargers of grid connected electric vehicle fleet was $0.9 \%$ in the OPTIMAL scenario and $0 \%$ in the MANUAL one (although some discharge was established in 45 hours within a year). This further proves that the operation of moderators is included in the optimal investment decision for sustainable national energy systems design, which has been already been demonstrated in [15].

\section{Discussion}

The advantages of the EPOPT method against the previously shown iterative one lies in its accuracy and user-friendliness. The reaching of planner defined accuracy of the optimal results is guaranteed by the complex algorithm and software implementation of the EPOPT method, while the iterative method may fail to find the optimum. There are three reasons for this:

1. The EPOPT method searches the whole $n$-dimensional domain of decision variables (where $\mathrm{n}$ is the number of decision variables), which may not be achieved with the iterative method for the $n>3$;

2. The EPOPT method performs five steps of the iterative method [19] simultaneously: the optimal mix of the renewable energy sources, the optimal mix of energy efficiency measures, the optimal mix of structural technical measures for increasing the flexibility of an energy system, different energy system design, and grid stabilization measures. All these five steps have impact on the criteria function, but also on the three constraint satisfaction functions. When done separately, these five steps could not satisfy any constraints. Together, however, they could. The equivalent impact of the simultaneous procedure on the criteria function may show a synergetic effect in the way that less investment is enough to reach designated goals. 
3. EPOPT method has a built-in feature of decreasing the flexibility gap based on utilization rates of the system components obtained in EnergyPLAN simulation for investment decision in GENOPT $®$, while the iterative method decreases the flexibility gap afterwards with additional effort and costs.

In a typical policy application software tools are used for modeling the results of investment action or inaction. In the EPOPT method the normative result is coupled with the level of minimal investment action among a variety of possible actions to make desirable change. Since the calculation of results from an action modelled by the EnergyPLAN are undisputable, the EPOPT method has no uncertainties in the domain of action and inaction.

\section{Conclusions}

Two methods for decreasing the flexibility gap in sustainable national energy systems have been presented in this paper. Using the same input assumptions, the two methods rendered different system structure solution calculations.

Two different perspectives for the planners' complex issues are solved in parallel: a sustainable system and a system with minimal costs. These two are united in the optimization method EPOPT in the form of constraints and goal function. If solved separately, as it is done when the heuristic iterative method is used, either sustainability or minimal costs may suffer.

The disadvantage of the heuristic iterative method lies in the limited number of decision vectors. The EPOPT method, on the other hand, uses an almost unlimited number of decision vectors in the process of energy system structure optimization. Further, the accuracy of the iterative method is lower in comparison to the EPOPT method, which happens because in the iterative method targets are reached successively rather than simultaneously. As a result, it might happen that either unnecessary or insufficient technical measures are applied for energy system transformation in an attempt to reach the designated goals. Fine-tuning of decision variables that takes place in such situations is time-consuming. The third disadvantage of the iterative method is that decreasing the flexibility gap in a separate step, after the system structure has been defined. In contrast, the EPOPT method incorporates this step into an optimal investment decision. Therefore the EPOPT method demonstrates improved accuracy, shorter duration (also user friendliness), and further cost reduction (better capacity utilization). The synergic interaction among a number of decision variables and designated targets is significant.

The EPOPT method enables the planners to design a techno-economically optimal structure of a national energy system influenced by hourly operation electricity market activities. Various exogenous assumptions on electricity price firstly affect the operation of simulated energy systems and later result in a different system structure.

\section{Acknowledgements}

This work is part of the research project "Smart Energy Grids" no. III 42009/2011, supported by the Ministry of Education and Science of the Republic of Serbia.

\section{References}


[1] Sterner M. Bioenergy and Renewable Power Methane In Integrated 100\% Renewable Energy Systems: Limiting Global Warming By Transforming Energy Systems: Kassel University Press, 2009.

[2] Pierre I, Bauer F, Blasko R, Dahlback N, Dumpelmann M, Kainurrine K, et al. Flexible generation: Backing up renewables. In: Scowcroft J, Nies S, editors. EURELECTRIC Renewables Action Plan (RESAP). Brussels: EURELECTRIC; 2011.

[3] Papaefthymiou G, Grave K, Dragoon K. Flexibility options in electricity systems. Ecofys; 2014.

[4] Denholm P, Hand M. Grid flexibility and storage required to achieve very high penetration of variable renewable electricity. Energy Policy. 2011;39(3):1817-30.

[5] Krakowski V, Assoumou E, Mazauric V, Maïzi N. Feasible path toward 40-100\% renewable energy shares for power supply in France by 2050: A prospective analysis. Applied Energy. 2016;171:501-22.

[6] Stadler I. Power grid balancing of energy systems with high renewable energy penetration by demand response. Utilities Policy. 2008;16(2):90-8.

[7] Hovland KM. Denmark's Wind Power Output Rises to Record in First Half. The Wall Street Journal2014.

[8] Vittrup C. 2013 was a record-setting year for Danish wind power. Energinet.dk; 2014.

[9] Mancarella P. MES (multi-energy systems): An overview of concepts and evaluation models. Energy. 2014;65(0):1-17.

[10] Lund H, Andersen AN, Østergaard PA, Mathiesen BV, Connolly D. From electricity smart grids to smart energy systems - A market operation based approach and understanding. Energy. 2012;42(1):96-102.

[11] SBC-EI. INTRODUCTION TO SMART GRIDS: SBC Energy Institute, 2015.

[12] Connolly D, Lund H, Mathiesen BV. Smart Energy Europe: The technical and economic impact of one potential $100 \%$ renewable energy scenario for the European Union. Renewable and Sustainable Energy Reviews. 2016;60:1634-53.

[13] Lannoye E, Flynn D, O'Malley M. Evaluation of Power System Flexibility. IEEE Transactions on Power Systems. 2012;27(2):922-31.

[14] Huber M, Dimkova D, Hamacher T. Integration of wind and solar power in Europe: Assessment of flexibility requirements. Energy. 2014;69(0):236-46.

[15] Bertsch J, Growitsch C, Lorenczik S, Nagl S. Flexibility in Europe's power sector An additional requirement or an automatic complement? Energy Economics. 2016;53:11831.

[16] Ma J. Evaluating and Planning Flexibility in a Sustainable Power System with Large Wind Penetration: The University of Manchester, 2012.

[17] Chandler H. Harnessing Variable Renewables. International Energy Agency; 2011.

[18] Dragoon K, Papaefthymiou G. Power System Flexibility Strategic Roadmap. Ecofys; 2015.

[19] Kempton W. Chapter 5 - Analysis: Large-Scale Integration of Renewable Energy. In: Lund $\mathrm{H}$, editor. Renewable Energy Systems. Boston: Academic Press; 2010. p. 75-125.

[20] SWECO. Study on the effective integration of Distributed Energy Resources for providing flexibility to the electricity system. 2015.

[21] Batas Bjelić I, Rajaković N, Ćosić B, Duić N. Increasing wind power penetration into the existing Serbian energy system. Energy. 2013;57(0):30-7.

[22] Haas R. Smart grids or smart solutions? plenary session at the SDEWES conference. Dubrovnik 2013.

[23] HIDALGO GONZALEZ I, RUIZ CASTELLO P, SGOBBI A, NIJS W, Quoilin S, ZUCKER A, et al. Addressing flexibility in energy system models. Publications Office of the European Union; 2015.

[24] Nickell BM. Wind Dispatchability and Storage-Interconnected Grid Perspective. Energy Efficiency \& Renewable Energy Department (EERE), Washington, DC. 2009.

[25] Denholm P, Ela E, Kirby B, Milligan M. The Role of Energy Storage with Renewable Electricity Generation. 1617 Cole Blvd. Golden, CO 80401-3393: National Renewable Energy Laboratory; 2010. 
[26] Mike D, Bob M, Baillie A. Transitioning from Traditional to Renewable Infrastructure. Policyholders' conference2010.

[27] Brouwer AS, van den Broek M, Zappa W, Turkenburg WC, Faaij A. Least-cost options for integrating intermittent renewables in low-carbon power systems. Applied Energy. 2016;161:48-74.

[28] Frew BA, Becker S, Dvorak MJ, Andresen GB, Jacobson MZ. Flexibility mechanisms and pathways to a highly renewable US electricity future. Energy. 2016;101:6578.

[29] Milligan M, Frew B, Zhou E, Arent DJ. Advancing System Flexibility for High Penetration Renewable Integration. National Renewable Energy Laboratory; 2015.

[30] Sučić S, Capuder T. Automation of flexible distributed multi-generation systems by utilizing optimized middleware platform. Applied Energy. 2016;169:542-54.

[31] Chandler H. Empowering Variable Renewables - Options for Flexible Electricity Systems. International Energy Agency; 2008.

[32] Tafarte P, Das S, Eichhorn M, Thrän D. Small adaptations, big impacts: Options for an optimized mix of variable renewable energy sources. Energy. 2014;72(0):80-92.

[33] Lund H, Mathiesen BV. The role of Carbon Capture and Storage in a future sustainable energy system. Energy. 2012;44(1):469-76.

[34] Futrell BJ, Ozelkan EC, Brentrup D. Optimizing complex building design for annual daylighting performance and evaluation of optimization algorithms. Energy and Buildings. 2015;92(0):234-45.

[35] Ferrara M, Fabrizio E, Virgone J, Filippi M. A simulation-based optimization method for cost-optimal analysis of nearly Zero Energy Buildings. Energy and Buildings. 2014;84(0):442-57.

[36] Bigot D, Miranville F, Boyer H, Bojic M, Guichard S, Jean A. Model optimization and validation with experimental data using the case study of a building equipped with photovoltaic panel on roof: Coupling of the building thermal simulation code ISOLAB with the generic optimization program GenOpt. Energy and Buildings. 2013.

[37] Đurić N. EnergyPlus and GenOpt in Thermo Technical Installations Design. KGH : Klimatizacija, grejanje, hlađenje : jugoslovenski naučno-stručni časopis za grejanje, hlađenje i klimatizaciju. 2005;34(3):25-8.

[38] Wetter M. GenOpt -Generic Optimization Program User Manual Version 3.1.0. Berkeley: Simulation Research Group Building Technologies Department Environmental Energy Technologies Division; 2011.

[39] Ćosić B, Krajačić G, Markovska N, Batas Bjelić I, Rajaković N, Duić N. 100\% Renewable Energy Solutions for Regions: the Case of South East Europe Energija, ekologija, ekonomija 2013;15(3-4):227-35.

[40] Gota D-I, Lund H, Miclea L. A Romanian energy system model and a nuclear reduction strategy. Energy. 2011;36(11):6413-9.

[41] Batas-Bjelic I, Rajakovic N, Cosic B, Duic N. A realistic EU vision of a lignite-based energy system in transition: Case study of Serbia. Thermal Science. 2015;19(2):371-82.

[42] Medic ZB, Cosic B, Duic N. Sustainability of remote communities: $100 \%$ renewable island of Hvar. Journal of Renewable and Sustainable Energy. 2013;5(4).

[43] Østergaard PA. Reviewing EnergyPLAN simulations and performance indicator applications in EnergyPLAN simulations. Applied Energy. 2015;154:921-33.

[44] EC. Conclusions on 2030 Climate and Energy Policy Framework. Brussels: European Council; 2014. p. 10.

[45] ${ }^{* * *}$. Draft Energy Sector Development Strategy of the Republic of Serbia for the period 2025 with projections by 2030. 2013.

[46] Lund $\mathrm{H}$. Flexible energy systems: integration of electricity production from CHP and fluctuating renewable energy. International Journal of Energy Technology and Policy. 2003;1(3):250-61.

[47] Sullivan P, Krey V, Riahi K. Impacts of considering electric sector variability and reliability in the MESSAGE model. Energy Strategy Reviews. 2013;1(3):157-63. 
[48] Thellufsen JZ, Lund $\mathrm{H}$. Energy saving synergies in national energy systems. Energy Conversion and Management. 2015;103:259-65.

[49] Lund H. EnergyPLAN Advanced Energy Systems Analysis Computer Model Documentation Version 11.0. Aalborg University, Denmark2013.

[50] Welsch M, Howells M, Bazilian M, DeCarolis JF, Hermann S, Rogner HH. Modelling elements of Smart Grids - Enhancing the OSeMOSYS (Open Source Energy Modelling System) code. Energy. 2012;46(1):337-50.

[51] Lund H, Werner S, Wiltshire R, Svendsen S, Thorsen JE, Hvelplund F, et al. 4th Generation District Heating (4GDH): Integrating smart thermal grids into future sustainable energy systems. Energy. 2014;68(0):1-11.

[52] Ilija Batas Bjelić, Nikola Rajaković, Goran Krajačić, Duić N. Valuing the moderation options in Serbia for higher wind penetrations. SDEWES. Venice-Istanbul: Faculty of Mechanical Engineering and Naval Architecture, Zagreb; 2014. p. 129.

[53] Kwon PS, Østergaard P. Assessment and evaluation of flexible demand in a Danish future energy scenario. Applied Energy. 2014;134(0):309-20.

[54] Batas Bjelić I, Rajaković N, Ćosić B, Duić N. Increasing wind power penetration into the existing Serbian energy system. Energy. 2013;57:30-7.

[55] Komušanac I, Ćosić B, Duić N. Impact of high penetration of wind and solar PV generation on the country power system load: The case study of Croatia. Applied Energy.

[56] Batas Bjelic I, Rajaković N, Krajačić G, Duić N. Decreasing the flexibility gap: transformation towards smart energy system in Serbia. Conference Decreasing the flexibility gap: transformation towards smart energy system in Serbia, Dubrovnik.

[57] Held A, Ragwitz M, Eichhammer W, Sensfuss F, Pudlik M, Pfluger B, et al. Estimating energy system costs of sectoral RES and EE targets in the context of energy and climate targets for 2030. 2014.

[58] Batas Bjelic I, Rajakovic N, Elsland R, Eichhammer W. Improvements of SerbianNEEAP based on analysis of residential electrlcity demand until 2030. Conference Improvements of Serbian-NEEAP based on analysis of residential electrlcity demand until 2030, Vienna. p. 1.

[59] Harmsen R, Wesselink B, Eichhammer W, Worrell E. The unrecognized contribution of renewable energy to Europe's energy savings target. Energy Policy. 2011;39(6).

[60] Ilija Batas Bjelić, Nikola Rajaković. The contribution of plug in electric vehicles and renewable energy sources achieving the national energy efficiency goals. ENEF 2015. Banja Luka2015. p. 17-9.

[61] Batas Bjelic I, Rajakovic N. Simulation-based optimization of sustainable national energy systems. Energy. 2015;91:1087-98.

[62] Bjelić IB. Simulation-based optimization of sustainable energy systems. Belgrade: University of Belgrade, 2016.

[63] Lambert T, Gilman P, Lilienthal P. Micropower System Modeling with Homer. Integration of alternative sources of energy: John Wiley \& Sons, Inc.; 2006. p. 379-418.

[64] Naylor TH, Finger JM, McKenney JL, Schrank WE, Holt CC. Verification of Computer Simulation Models. Management Science. 1967;14(2):B92-B106.

[65] Popper K. The logic of scientific discovery: Routledge, 2005.

[66] Cowhey PF. The problems of plenty: Energy policy and international politics. 1985.

Table 1 Scenario input assumptions and decision variables (names based on [61])

\begin{tabular}{|c|c|c|c|}
\hline Name & Unit & OPTIMAL & MANUAL \\
\hline Market price & $€ / M W h$ & \multicolumn{2}{|c|}{65} \\
\hline
\end{tabular}




\begin{tabular}{|c|c|c|c|}
\hline Operation optimization & & \multicolumn{2}{|c|}{ Market } \\
\hline Interest & $\%$ & \multicolumn{2}{|c|}{10} \\
\hline CO2 price & $€ / t$ & \multicolumn{2}{|c|}{30} \\
\hline Lignite & $€ / G J$ & \multicolumn{2}{|c|}{1.45} \\
\hline Fueloil & $€ / G J$ & \multicolumn{2}{|c|}{10.76} \\
\hline Natural gas & $€ / G J$ & \multicolumn{2}{|c|}{4.87} \\
\hline Biomass & $€ / G J$ & \multicolumn{2}{|c|}{2.66} \\
\hline Petrol jetpetrol & $€ / G J$ & \multicolumn{2}{|c|}{16.2} \\
\hline Gasoline diesel & $€ / G J$ & \multicolumn{2}{|c|}{14.8} \\
\hline LPG & $€ / G J$ & \multicolumn{2}{|c|}{11.27} \\
\hline Dry biomass & $€ / G J$ & \multicolumn{2}{|c|}{2.5} \\
\hline Wet biomass & $€ / G J$ & \multicolumn{2}{|c|}{2.5} \\
\hline WIND & MW & 1093.75 & 2810 \\
\hline PV & MW & 0 & 2240 \\
\hline SHPP & MW & 750 & 750 \\
\hline SavingCoalRef & TWh & 0.45 & 1 \\
\hline SwitchCoalGas & TWh & 0.003906 & 0.003906 \\
\hline SwitchCoalBiomass & TWh & 0.5 & 0.5 \\
\hline SavingHeatRef & TWh & 0 & 2 \\
\hline SavingHeatNetw & TWh & 0 & 1 \\
\hline IndustrialCHP & TWh & 1 & 1 \\
\hline SwitchEHDH & TWh & 0.03125 & 0.03125 \\
\hline SavingElecCable & TWh & 1 & 1 \\
\hline SwitchElecSolarWH & TWh & 2 & 2 \\
\hline DemandResponse & TWh & 1.8125 & 3.17 \\
\hline SavingGasInd & TWh & 2 & 2 \\
\hline ElecPHEVSmart & TWh & 1 & 3.2 \\
\hline BioDiesel & TWh & 0 & 0 \\
\hline newTPPsize & MW & 0 & 0 \\
\hline
\end{tabular}




\begin{tabular}{|c|c|c|c|}
\hline oldTPPsize & MW & 2006.313 & 2006.313 \\
\hline newCHPsize & MW & 360.9375 & 360.9375 \\
\hline oldCHPsize & MW & 87.5 & 87.5 \\
\hline StorageP & MW & 650 & 650 \\
\hline Transmission & MW & 3600 & 3600 \\
\hline
\end{tabular}

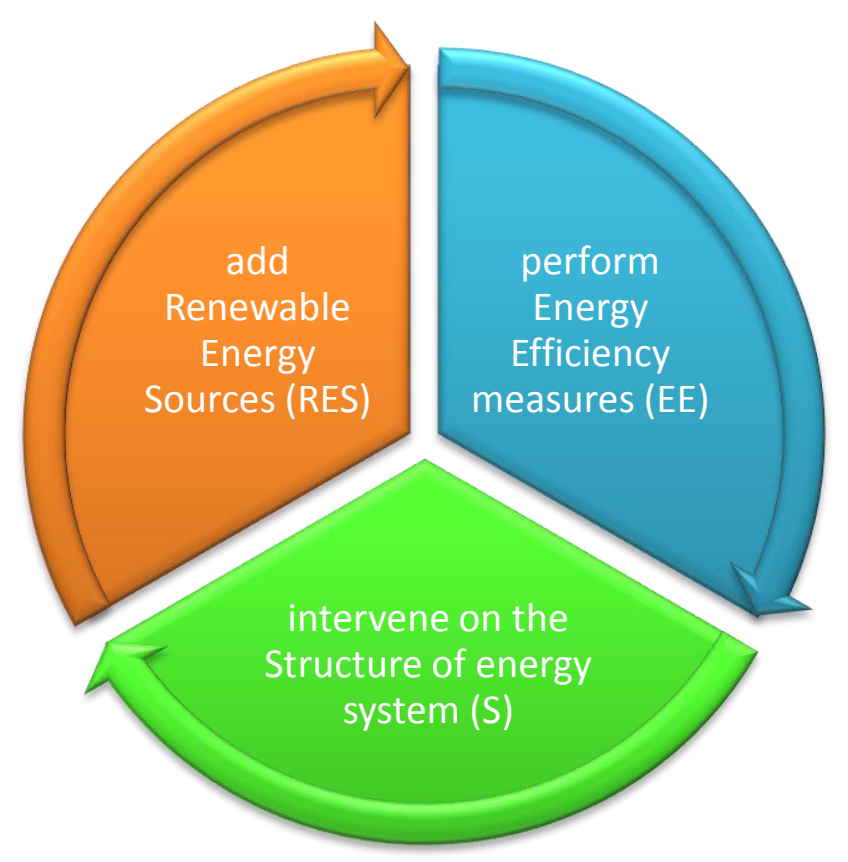

Figure $1 \mathrm{~A}$ decision vectors for the transformation of an nation energy system toward sustainable one. 

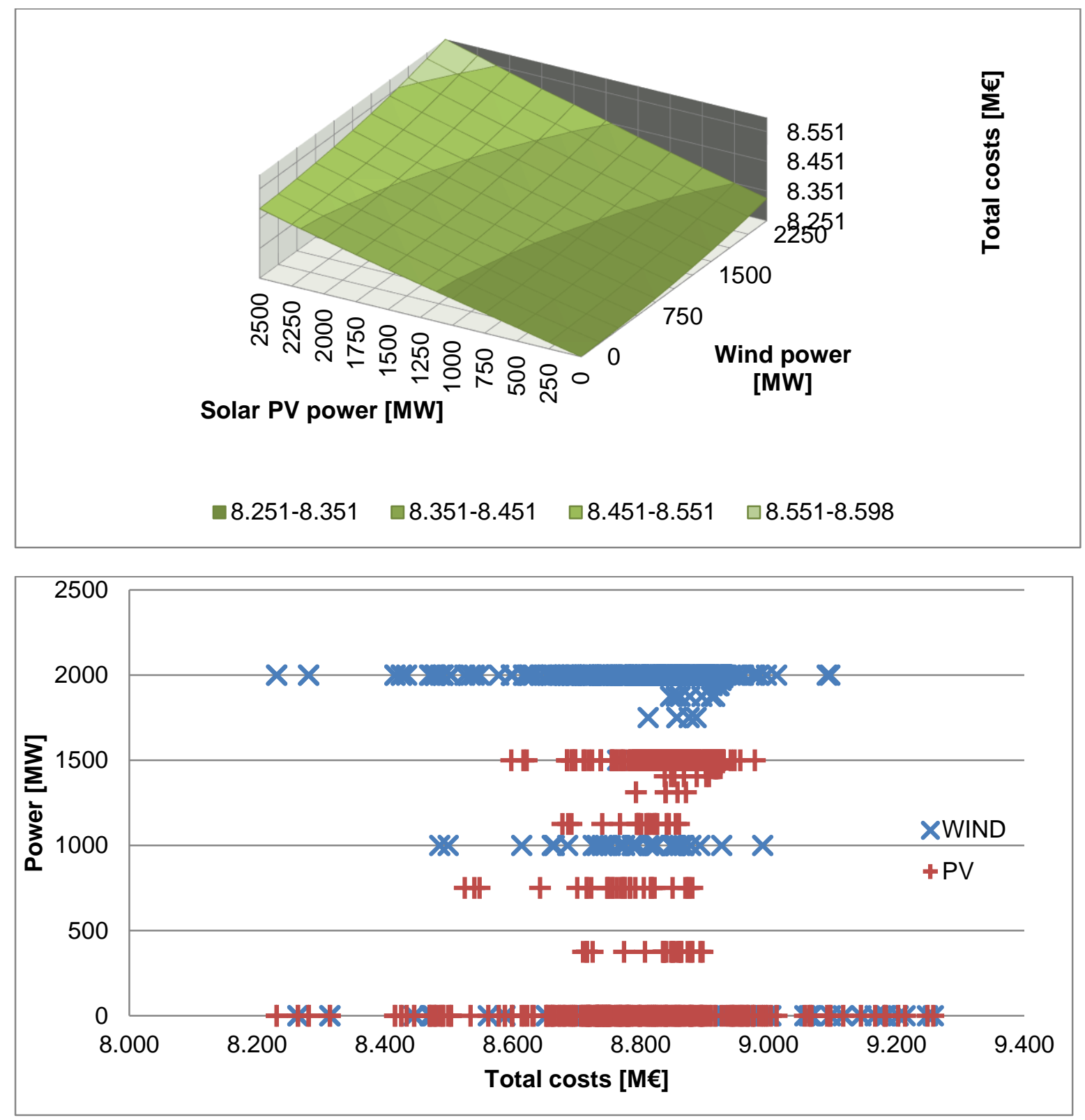

Figure 2 The results of the iterative method (left), and of the optimization method (right) for total costs minimization by variation of two decision variables: solar PV power and wind power. For the constant values of decision variables total costs are constant on the left, but in contrary they are varying on the right. 


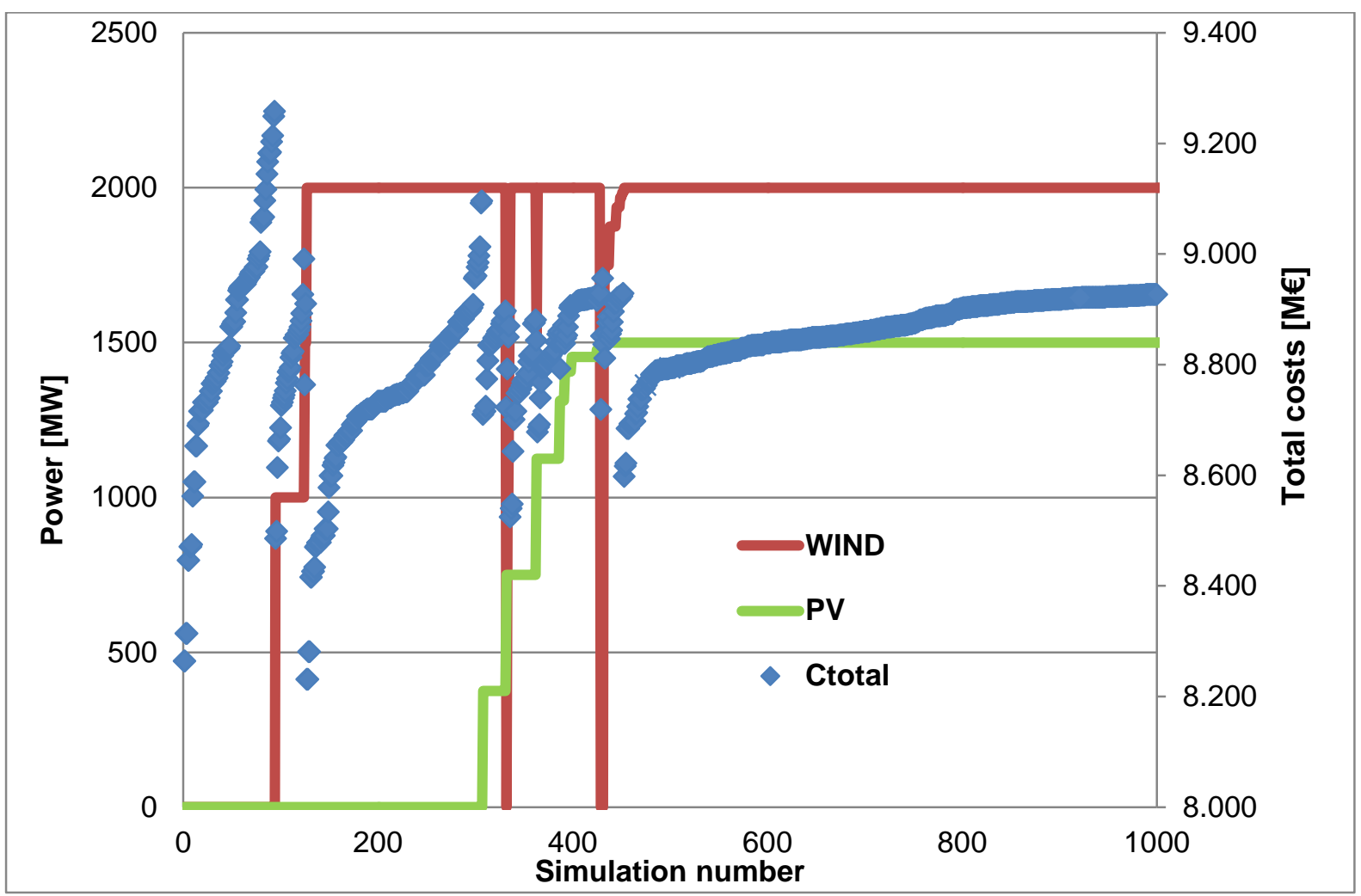

Figure 3 The variation of the total costs in the different simulation numbers during the optimization method. 


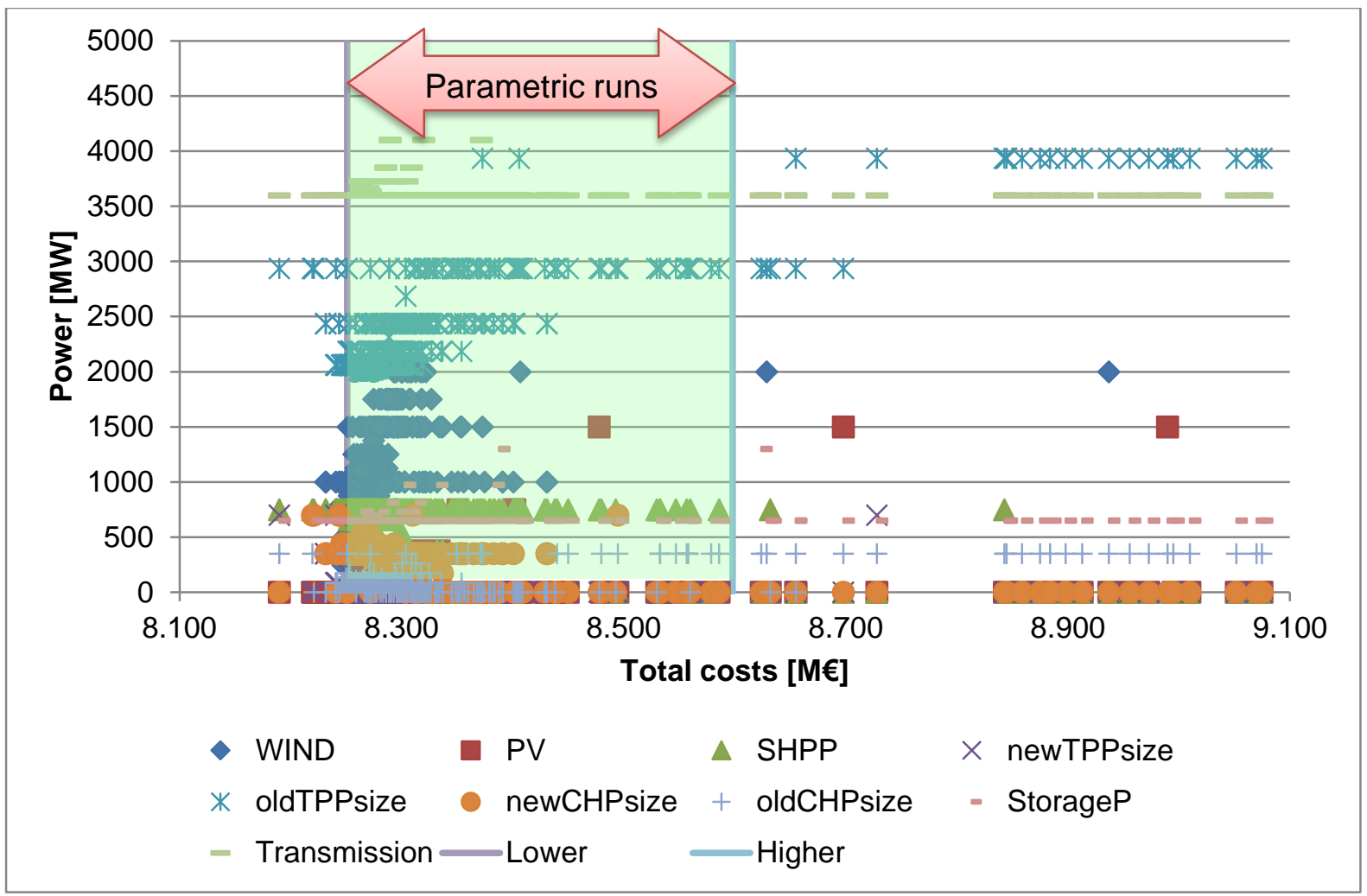

Figure 4 The results of EPOPT method for the minimization of total costs. Variation of multiple decision variables, decision vectors.

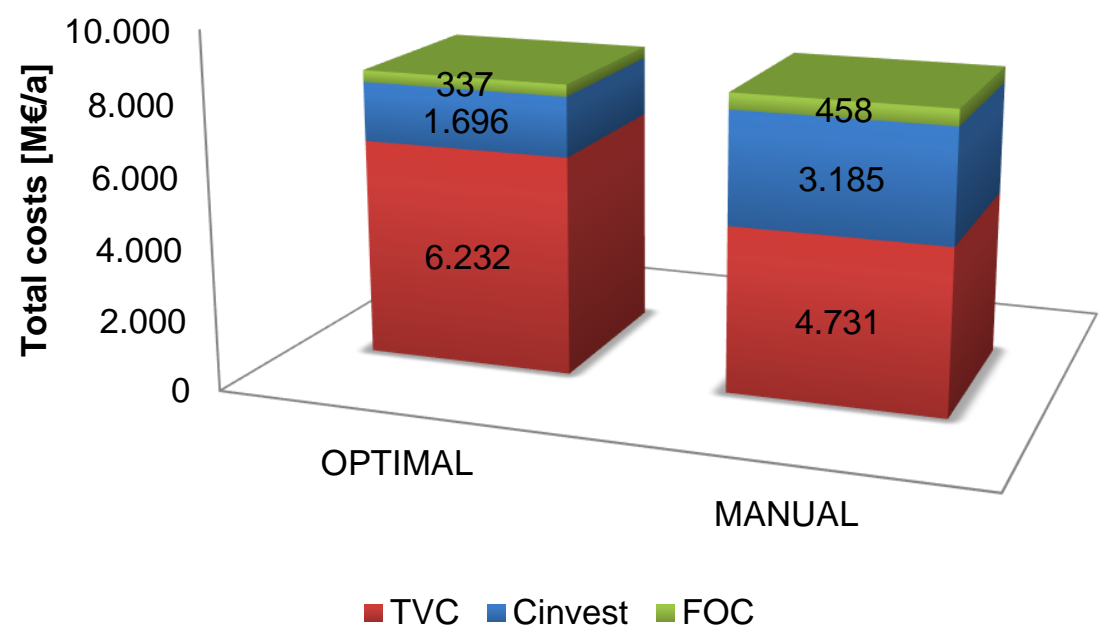

Figure 5 Financial balance: Comparison of total cost structure for the OPTIMAL and MANUAL scenario. TVC-total variable costs, Cinvest-investment costs, FOC-fixed operational costs. 


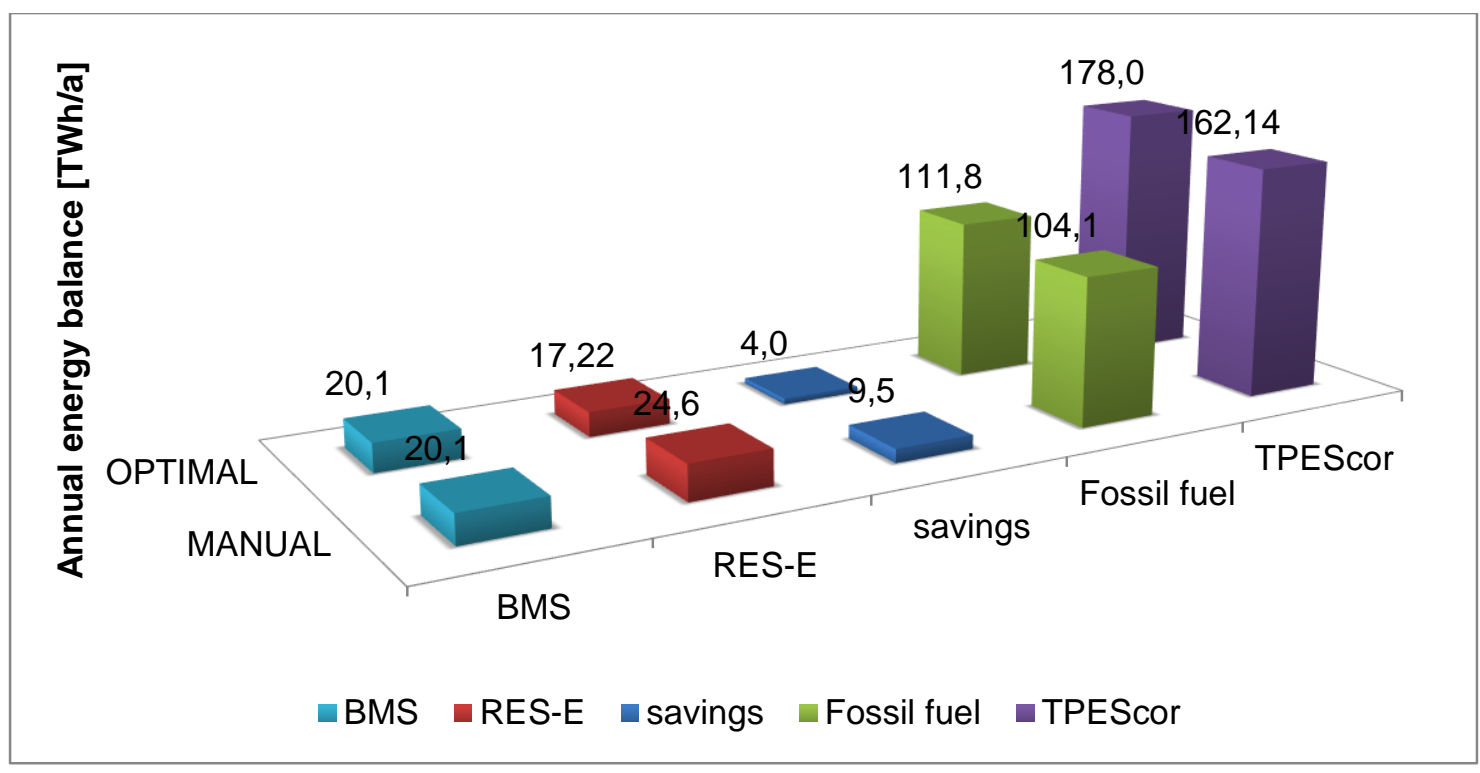

Figure 6 Energy balance: The comparison of annual energy balance structure for the OPTIMAL and MANUAL scenario. RES-E- renewable electricity sources, BMS-biomass, Fossil fuel-total fossil fuel consumption, savings-total annual savings, TPEScor-import/export corrected TPES value.

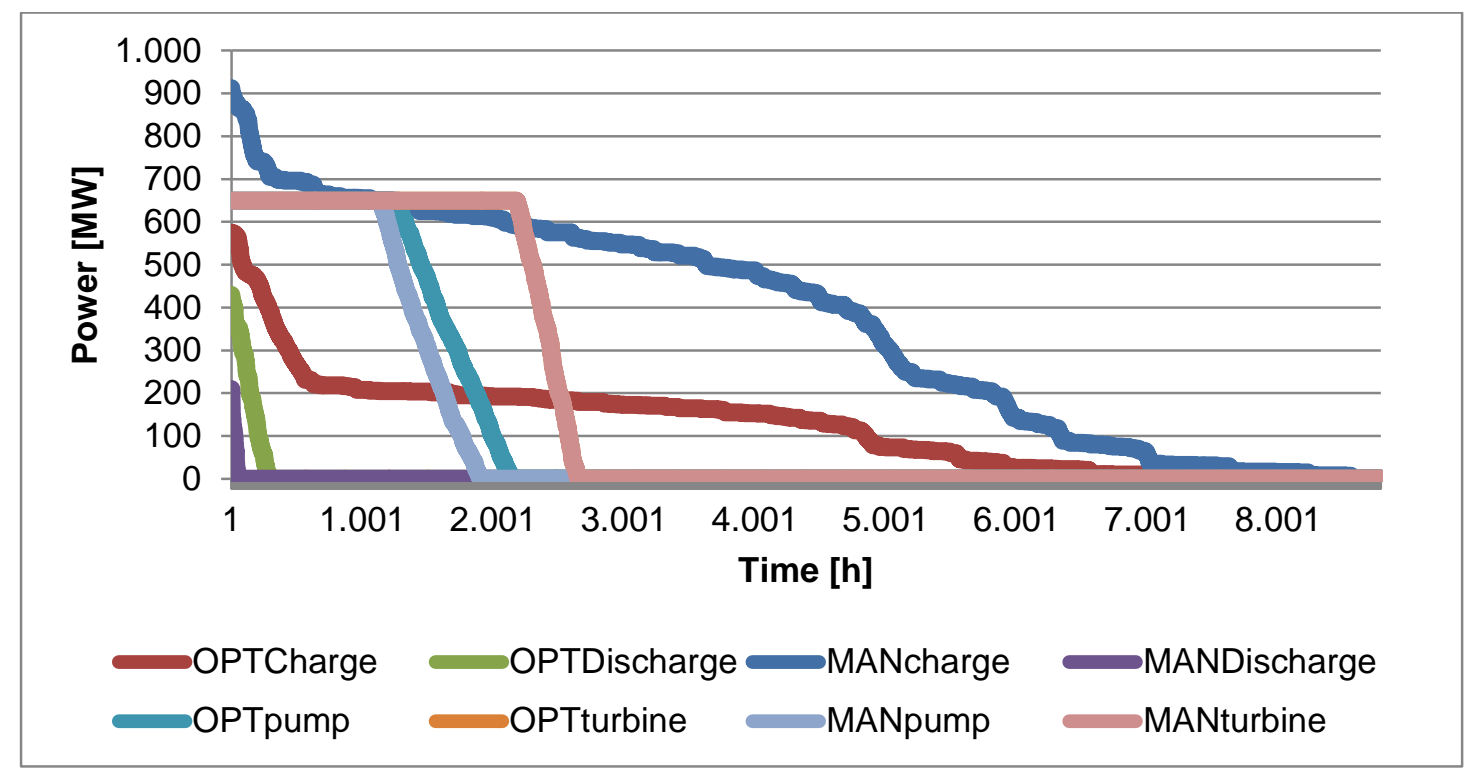

Figure 7 Annual operation duration curve of pump/turbine in PHSPP plant and charge/discharge of grid connected electric vehicle. OPT-OPTIMAL, MAN-MANUAL. 